\title{
Further validation of the Motivation for Traumatic Brain Injury Rehabilitation Questionnaire (MOT-Q) in patients with acquired brain injury
}

\author{
Citation for published version (APA):
}

Boosman, H., van Heugten, C. M., Winkens, I., Smeets, S. M. J., \& Visser-Meily, J. M. (2016). Further validation of the Motivation for Traumatic Brain Injury Rehabilitation Questionnaire (MOT-Q) in patients with acquired brain injury. Neuropsychological Rehabilitation, 26(1), 87-102.

https://doi.org/10.1080/09602011.2014.1001409

Document status and date:

Published: 02/01/2016

DOI:

10.1080/09602011.2014.1001409

Document Version:

Publisher's PDF, also known as Version of record

Document license:

Taverne

Please check the document version of this publication:

- A submitted manuscript is the version of the article upon submission and before peer-review. There can be important differences between the submitted version and the official published version of record.

People interested in the research are advised to contact the author for the final version of the publication, or visit the DOI to the publisher's website.

- The final author version and the galley proof are versions of the publication after peer review.

- The final published version features the final layout of the paper including the volume, issue and page numbers.

Link to publication

\footnotetext{
General rights rights.

- You may freely distribute the URL identifying the publication in the public portal. please follow below link for the End User Agreement:

www.umlib.nl/taverne-license

Take down policy

If you believe that this document breaches copyright please contact us at:

repository@maastrichtuniversity.nl

providing details and we will investigate your claim.
}

Copyright and moral rights for the publications made accessible in the public portal are retained by the authors and/or other copyright owners and it is a condition of accessing publications that users recognise and abide by the legal requirements associated with these

- Users may download and print one copy of any publication from the public portal for the purpose of private study or research.

- You may not further distribute the material or use it for any profit-making activity or commercial gain

If the publication is distributed under the terms of Article 25fa of the Dutch Copyright Act, indicated by the "Taverne" license above, 


\section{Neuropsychological Rehabilitation}

\section{An International Journal}

taven

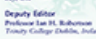

Hileen Boosman, Caroline M van Heugten, leke Winkens, Sanne MJ Smeets \& Johanna MA Visser-Meily

To cite this article: Hileen Boosman, Caroline M van Heugten, leke Winkens, Sanne MJ Smeets \& Johanna MA Visser-Meily (2016) Further validation of the Motivation for Traumatic Brain Injury Rehabilitation Questionnaire (MOT-Q) in patients with acquired brain injury, Neuropsychological Rehabilitation, 26:1, 87-102, DOI: 10.1080/09602011.2014.1001409

To link to this article: https://doi.org/10.1080/09602011.2014.1001409

Published online: 20 Jan 2015.

Submit your article to this journal

山ll Article views: 622

Q View related articles 두

View Crossmark data $₫$

Citing articles: 6 View citing articles $ऍ$ 


\title{
Further validation of the Motivation for Traumatic Brain Injury Rehabilitation Questionnaire (MOT-Q) in patients with acquired brain injury
}

\author{
Hileen Boosman ${ }^{1}$, Caroline M van Heugten ${ }^{2,3}$, \\ Ieke Winkens ${ }^{2}$, Sanne MJ Smeets ${ }^{2}$, and \\ Johanna MA Visser-Meily ${ }^{1}$
}

${ }^{1}$ Brain Center Rudolf Magnus and Center of Excellence for Rehabilitation Medicine, University Medical Center Utrecht and De Hoogstraat Rehabilitation, Utrecht, The Netherlands.

${ }^{2}$ Maastricht University, Department of Psychiatry and Neuropsychology, School for Mental Health and Neuroscience, Maastricht, The Netherlands ${ }^{3}$ Maastricht University, Department of Neuropsychology and Psychopharmacology, Faculty of Psychology and Neuroscience, Maastricht, The Netherlands

(Received 9 July 2014; accepted 17 December 2014)

The Motivation for Traumatic Brain Injury Rehabilitation Questionnaire (MOT-Q) evaluates motivation for rehabilitation in four subscales: Interest in rehabilitation, Lack of anger, Lack of denial, and Reliance on professional help. The objective of this study was to further validate the MOT-Q in 122 inpatients and 92 outpatients with acquired brain injury (ABI). The main measures were motivation for rehabilitation (MOT-Q), self-awareness (Patient Competency Rating Scale), and treatment motivation (Visual Analogue Scale). The MOT-Q showed adequate feasibility in terms of few items with missing responses and few undecided responses. We found no

Correspondence should be addressed to Johanna MA Visser-Meily, Department of Rehabilitation, Nursing Science and Sport, Rudolf Magnus Institute of Neuroscience, P.O. Box 85500, 3508 GA Utrecht, The Netherlands. E-mail: j.m.a.visser-meily@umcutrecht.nl

This study is funded by Achmea Healthcare Foundation and the National Initiative Brain and Cognition (NIBC). This quick-result project is embedded in the pillar "The Healthy Brain, Program Cognitive Rehabilitation" [grant number 056-11-014]. The authors would like to thank the participating rehabilitation centres: Adelante Zorggroep, Hoensbroek; De Hoogstraat Rehabilitation, Utrecht; Reade, Rehabilitation Centre, Amsterdam; Rijndam Rehabilitation, Rotterdam; Rehabilitation Centre Tolbrug, 's-Hertogenbosch.

(C) 2015 Taylor \& Francis 
floor or ceiling effects, and significant item-total MOT-Q correlations for 29 of 31 items. Internal consistency was good for the MOT-Q total and acceptable to good for the subscales. The MOT-Q scores were significantly intercorrelated except for the subscales Lack of denial and Reliance on professional help in the inpatient group. The MOT-Q total and subscales were significantly associated with treatment motivation. The Lack of denial subscale showed no significant association with treatment motivation and no to moderate significant associations with self-awareness. In conclusion, the overall MOT-Q is a valid instrument to assess motivation for rehabilitation in patients with ABI. Further research is needed to examine the validity of the subscales.

Keywords: Adult; Psychometry; Brain injury; Behaviour; Behaviour mechanisms; Stroke.

\section{INTRODUCTION}

Low motivation is a frequently observed phenomenon in patients with acquired brain injury (ABI), that can affect their commitment and perseverance in treatment (Al-Adawi, Powell, \& Greenwood, 1998; Marin \& Wilkosz, 2005). Anecdotal and research evidence suggests that motivation is an important determinant of rehabilitation outcome in patients with ABI (Lenze et al., 2004; Maclean, Pound, Wolfe, \& Rudd, 2002; Medley \& Powell, 2010; Van den Broek, 2005; Winkens, Van Heugten, Visser-Meily, $\&$ Boosman, 2014). Not surprisingly, there is a growing number of therapeutic approaches aimed at enhancing motivation (e.g., motivational interviewing; Medley \& Powell, 2010). An area of research that has received limited attention in the literature is the assessment of motivation for ABI rehabilitation. As a consequence, motivation is mostly determined informally or implicitly based on clinical judgement (Maclean et al., 2002). The criteria clinicians use to identify low motivation are, however, often unclearly defined (Maclean et al., 2002). Standardised instruments can be used to aid the assessment of motivation.

At present, there are relatively few instruments that were specifically developed to assess motivation for rehabilitation in a brain injury population. On the one hand, there are clinician-rated instruments that evaluate patient engagement or participation during therapy, such as the Pittsburgh Rehabilitation Participation Scale (PRPS; Lenze et al., 2004) and the Rehabilitation Therapy Engagement Scale (RTES; Lequerica, Rapport, Whitman, \& Millis, 2006). These instruments basically focus on the observable part of patient motivation. For instance, does the patient show maximal effort in most exercises or is much encouragement required to finish exercises 
(Lenze et al., 2004)? On the other hand, there are patient-rated (i.e., selfreport) instruments such as the Motivation for Traumatic Brain Injury Rehabilitation Questionnaire (MOT-Q; Chervinsky et al., 1998). Patient-rated questionnaires address motivation from the patient's perspective.

Patient-rated instruments can be used to explore potential underlying causes of low participation during therapy (e.g., no interest in rehabilitation or limited family support). This information may eventually aid the development or improvement of treatment programmes to target low motivation. The MOT-Q was specifically developed to measure patients' perceptions of their illness and rehabilitation (Chervinsky et al., 1998). The MOT-Q evaluates multiple barriers of motivation for rehabilitation in four subscales: Interest in rehabilitation, Lack of anger, Lack of denial, and Reliance on professional help. Previous studies have already shown that the overall MOT-Q has good internal consistency in patients with traumatic brain injury (TBI) $(\alpha=.91)$ (Chervinsky et al., 1998) and ABI $(\alpha=.86)$ (Bains, Powell, \& Lorenc, 2007). On a critical note, however, in the first study the MOT-Q was validated using the same study sample that was used for development of the scale. The sample consisted of predominantly male (91\%) military personnel with traumatic brain injury who were, on average, 30 years of age and 5.5 months postinjury (Chervinsky et al., 1998). In the second study, the internal consistency of the MOT-Q was evaluated in a rather small sample of 40 patients with ABI as part of a broader study on predicting engagement in rehabilitation (Bains et al., 2007). Although these studies have already shown evidence of validity, further psychometric validation is required before the MOT-Q can be adopted for use in patients with $A B I$. The aim of this study was therefore to evaluate further the psychometric properties of the MOT-Q in ABI rehabilitation in terms of feasibility, floor and ceiling effects, item-total correlations, intercorrelations between MOT-Q total and subscale scores, internal consistency, and criterion validity. Two different patient populations were included: inpatients with ABI, and outpatients with behavioural or emotional problems following ABI. This was done to obtain a larger study sample and to facilitate the comparison of results with previous studies. The initial validation study (Chervinsky et al., 1998) consisted of patients with TBI of whom many had neuropsychiatric problems (e.g., more than one quarter of patients had elevated scores for hypochrondriasis, depression and hypomania). The other study included a mixed group of inpatients and outpatients with ABI (Bains et al., 2007).

\section{Hypotheses}

We hypothesised that the distribution of scores would demonstrate an absence of floor and ceiling effects, and that the MOT-Q total and subscale scores would have adequate internal consistency and large intercorrelations. We 
expected that the MOT-Q total score would be significantly, positively associated with all MOT-Q items and with a Visual Analogue Scale (VAS-scale) of treatment motivation. Further, we hypothesised that the Lack of denial subscale would show a significant, inverse association with awareness of deficits. We expected similar results for the inpatient and outpatient group.

\section{METHODS}

\section{Participants}

An inpatient and an outpatient group were examined. Patients in the inpatient group were part of a longitudinal, prospective cohort study examining factors influencing outcome of ABI rehabilitation. These patients were recruited between November 2012 and December 2013 from inpatient clinics of five rehabilitation centres in The Netherlands. Inpatients were included if they met the following inclusion criteria: (1) diagnosis of ABI based on medical records; and (2) $\geq 18$ years of age. Exclusion criteria were: (1) severe aphasia based on a Dutch Aphasia Foundation (Deelman, Koning-Haanstra, Liebrand, \& Van de Burg, 1987) scale score less than four, or clinical judgement; (2) insufficient command of the Dutch language based on clinical judgement (3) premorbid psychiatric disorder or substance abuse for which hospital admission was necessary; (4) minimally conscious state at the time of assessment; (5) post-traumatic amnesia at the time of assessment; (6) degenerative or progressive brain disease; (7) active participation in other studies to avoid participation burden; and (8) no informed consent.

Patients in the outpatient group were recruited from consecutive admissions during the period from September 2010 to January 2012 from outpatient units of four mental health centres in The Netherlands. The inclusion criteria for the outpatient group were: (1) diagnosis of ABI based on medical records; (2) $\geq 18$ years of age; (3) behavioural or emotional problems following ABI based on clinical judgement; and (4) $\geq 6$ months post-injury to ensure that patients were in a stable phase after their injury in which spontaneous recovery was no longer likely. Exclusion criteria were: (1) insufficient command of the Dutch language; (2) inability to complete the questionnaires based on clinical judgement; (3) degenerative brain disease or whiplash; and (4) no informed consent. For both patient groups, the treating neuropsychologist of each patient participated in the study.

\section{Measures}

Motivation. The MOT-Q (Chervinsky et al., 1998) is a 31-item self-report questionnaire used to assess the desire and interest to undertake rehabilitation. The MOT-Q was originally developed for patients with TBI. Its items reflect 
components of insight and good emotional adjustment that may directly relate to engagement or motivation for rehabilitation. The MOT-Q was originally validated against the Minnesota Multiphasic Personality Inventory-2 (MMPI-2; Butcher, Dahlstrom, Graham, Tellegen, \& Kaemmer, 1989) in a TBI population. The MOT-Q was translated into Dutch using a forwardbackward translation procedure (Smeets et al., 2014). The MOT-Q instruction states that "rehabilitation programmes are designed to help injured persons recover from their illness" and that "Rehabilitation includes: physical therapy, speech therapy, counselling or psychotherapy, occupational therapy, vocational services, and cognitive therapy" (Chervinsky et al., 1998).

The questionnaire contains four subscales:

(1) Interest in rehabilitation. This 7-item subscale measures patients' interest in and positive expectations of rehabilitation. An example item is, "I'm very excited about getting treatment as soon as possible".

(2) Lack of anger. This 10-item subscale assesses absence of anger and hostility towards therapists and rehabilitation. An example item is, "Therapists would waste my time".

(3) Lack of denial. This 8-item subscale measures absence of denial of deficits. In other words, acceptance and awareness of impairments. An example item is, "I'm better now than I ever was".

(4) Reliance on professional help. This 6-item subscale assesses patients' attitudes towards professionals and their willingness to follow treatment advice. An example item is, "Doctors know what I need and I'll do what they say".

Items are rated on a 5-point scale ranging from -2 (strongly disagree) to 2 (strongly agree) with a score of 0 being undecided. Total scores range between -62 and 62. Higher scores indicate higher motivation for rehabilitation.

The outpatient group was the first Dutch sample that completed the MOT-Q. Therefore, outpatients also completed a Visual Analogue Scale (VAS) of treatment motivation as a control measure. Patients were asked to rate their level of treatment motivation on a $10 \mathrm{~cm}$ line that ranged from 0 (not at all motivated) to 10 (very motivated). The absolute rating was used as outcome.

Self-awareness. The Patient Competency Rating Scale (PCRS; Prigatano et al., 1986) assesses self-awareness using a self-other discrepancy method. The PCRS contains 30 items that cover four domains: activities of daily living, behavioural and emotional functioning, cognitive abilities, and physical functioning. All items are rated on a 5-point scale ranging from 1 (cannot do) to 5 (can do with ease). An informant rating was obtained from the patient's neuropsychologist. Awareness scores were obtained by calculating 
the discrepancy in ratings between the patient and the neuropsychologist. Discrepancy scores range from - 120 to 120 with greater discrepancies indicating poorer self-awareness. Positive discrepancies indicate overestimation and negative discrepancies indicate underestimation of difficulties. The PCRS has good reliability and validity in patients with acquired brain injury (Smeets, Ponds, Verhey, \& Van Heugten, 2012).

\section{Procedure}

In the inpatient group, eligibility criteria were confirmed by the treating rehabilitation physician. The MOT-Q and PCRS were administered within approximately two weeks of enrollment. The medical ethics committee of the University Medical Centre Utrecht and the five participating rehabilitation centres approved the study protocol.

In the outpatient group, a neuropsychologist at each institute screened patients for eligibility during the first interview with the patients at the mental health centre. After participants provided written informed consent, demographic and disease characteristics were obtained from their medical records. The MOT-Q, VAS Treatment Motivation, and PCRS were administered during regular neuropsychological assessment at the start of the diagnostic procedure. The Medical Ethics Committee of Maastricht University Medical Centre and the research committees of each of the participating institutions approved the procedure.

All inpatients and outpatients gave informed consent. After participants provided written informed consent, demographic and disease characteristics were obtained from their medical records. For inpatients, ADL dependence was assessed using the Barthel Index (Wade \& Collin, 1988) score at admission to the rehabilitation centre. It has a 0-20 range for which a higher score reflects better functioning. The treating neuropsychologist of each patient completed the PCRS.

\section{Statistical analysis}

The distribution of MOT-Q total and subscale scores was evaluated using Kolmogorov Smirnov tests. In case of a not normally distributed MOT-Q total or subscale score, non-parametric analyses were used for all analyses. Feasibility of the MOT-Q was assessed by counting the number of missing values. Also, items for which more than $40 \%$ of patients chose the answer "undecided" ( score $=0$ ) were reported because these can also be considered a "non-response" answer. For further analyses, up to $25 \%$ missing values for each subscale of the MOT-Q and PCRS was permitted. These were replaced with the mean of the non-missing values within the same subscale. Floor or ceiling effects were considered present if more than $15 \%$ of all patients obtained the lowest or highest possible score (Terwee et al., 2007). To 
examine whether all MOT-Q items and the four subscales measure the same construct, Pearson or Spearman correlations were computed between the items and the MOT-Q total score and between the MOT-Q total and subscales. Internal consistency was assessed using Cronbach's $\alpha$. Coefficients below .6 were considered poor, between .6 and .7 acceptable, between .7 and .9 good, and coefficients exceeding .9 as excellent. Criterion validity of the MOT-Q was examined by calculating Pearson or Spearman correlations between the MOT-Q scores and the VAS Treatment Motivation and between Lack of denial and the PCRS discrepancy score. Correlations between .30 and .49 were considered moderate and correlations exceeding .50 as large (Cohen, 1988). Alpha was set at .05. Data were analysed using SPSS version 21.0.

\section{RESULTS}

\section{Participants}

In the inpatient group, 125 patients were recruited from the five rehabilitation centres (response rate $78.1 \%$ ). Of these, three patients were excluded for the current study because they did not complete the MOT-Q due to early discharge $(n=1)$ or withdrew from the study $(n=2)$. A total of 122 patients was included. Most patients suffered non-traumatic brain injury $(73.4 \%)$, in particular stroke $(59.1 \%)$. The mean Barthel Index (BI) was $15.3(S D=4.9 ; n=111) ; 62.1 \%$ of patients were ADL independent or mildly disabled (BI 15-20) and $37.8 \%$ were moderately to severely ADL disabled (BI 0-14). The majority of inpatients had a medium to high level of education $(82.8 \%)$ and most inpatients were above 50 years of age $(64.8 \%)$. The majority of inpatients were assessed within three months post-ABI $(89.3 \%)$.

In the outpatient group, 93 patients were recruited from the four mental health centres (response rate 91.2\%). Of these, one patient was excluded for the current study because that patient did not complete the MOT-Q. Most outpatients were assessed at least one year post-ABI (89.2\%). Three patients were included whose brain injury occurred less than six months previously. Based on clinical judgement these patients were already in a stable phase after their injury in which spontaneous recovery was no longer likely. A total of 92 patients was included in this study. Of these, 54.3\% suffered non-traumatic brain injury and $45.7 \%$ traumatic brain injury. There were relatively more patients with traumatic brain injury in the outpatient group compared to the inpatient group (45.7\% and $23.0 \%$, respectively). The main Diagnostic and Statistical Manual of Mental Disorders (DSM) diagnosis was cognitive disorder (81.5\%). The mean Global Assessment of 
Functioning (GAF) score (54.5) indicated moderate psychiatric symptoms or moderate difficulty in social, occupational, or school functioning. More information about outpatients' psychiatric symptoms can be found elsewhere (Smeets et al., 2014). Table 1 shows the sample characteristics for both patient groups.

\section{Distribution of scores}

In Table 2 descriptive statistics for the MOT-Q total and subscales are presented. The median MOT-Q total score for the inpatient group was 25.4 (range -22 to 51) and for the outpatient group 17.0 (range -49 to 51). In both patient groups, the MOT-Q total score was normally distributed. The subscales Lack of denial, Interest in rehabilitation, and Reliance on professional help, showed a left-skewed, non-normal distribution. The Lack of anger subscale showed a normal distribution in the outpatient group and a non-normal distribution in the inpatient group. Hence, non-parametric statistics were used for all analyses.

\section{Feasibility}

In the inpatient group, $97.5 \%$ of patients answered all $31 \mathrm{MOT}-\mathrm{Q}$ items. The remaining $2.5 \%$ had only one missing item. Which specific item was missed

TABLE 1

Characteristics of the study population

\begin{tabular}{lcc}
\hline & Inpatient group $(\mathrm{N}=122)$ & Outpatient group $(\mathrm{N}=92)$ \\
\hline Gender, \% male $(n)$ & $57.4 \%(70)$ & $67.4 \%(62)$ \\
Mean age in years $(S D)$ & $53.7(13.2)$ & $45.5(12.7)$ \\
Age range & $20-78$ & $18-76$ \\
Education, \% $(n)$ & & \\
$\quad$ Low & $17.2 \%(21)$ & $45.7 \%(42)$ \\
Medium & $38.5 \%(47)$ & $29.3 \%(27)$ \\
High & $44.3 \%(54)$ & $25.0 \%(23)$ \\
Diagnosis, \% $(n)$ & & \\
$\quad$ Traumatic brain injury & $23.0 \%(29)$ & $45.7 \%(42)$ \\
Cerebrovascular accident & $59.1 \%(72)$ & $30.4 \%(28)$ \\
Neuro-inflammatory disease & $4.1 \%(5)$ & $3.3 \%(3)$ \\
Post-anoxic brain damage & $4.9 \%(6)$ & $1.1 \%(1)$ \\
Tumour & $7.4 \%(9)$ & $7.6 \%(7)$ \\
Other & $0.8 \%(1)$ & $11.9 \%(11)$ \\
Mean time post-injury $(S D)$ & $53.8(37.3)$ days & $10.9(10.9)$ years \\
Range & $20-269$ days & $0.3-41.9$ years \\
Mean Barthel Index at admission $(S D)^{\mathrm{a}}$ & $15.3(4.9)$ & - \\
\hline
\end{tabular}

${ }^{a}$ The Barthel Index was available for 111 of 122 inpatients. 
TABLE 2

Descriptives and floor and ceiling effects of the MOT-O

\begin{tabular}{|c|c|c|c|c|c|c|c|}
\hline MOT- $Q$ variable & $\begin{array}{c}\text { Possible } \\
\text { score range }\end{array}$ & $\begin{array}{l}\text { Min-max } \\
\text { score }\end{array}$ & Median & $I Q R$ & $\begin{array}{l}\text { Kolmogorov- } \\
\text { Smirnov }\end{array}$ & $\begin{array}{c}\text { \% lowest } \\
\text { score }\end{array}$ & $\begin{array}{c}\% \text { highest } \\
\text { score }\end{array}$ \\
\hline \multicolumn{8}{|l|}{ Inpatient group } \\
\hline MOT-Q total & -62 to 62 & -22 to 51 & 25.4 & 16.0 & .07 & $0 \%$ & $0 \%$ \\
\hline $\begin{array}{l}\text { Interest in } \\
\quad \text { rehabilitation }\end{array}$ & -14 to 14 & -5 to 14 & 8.0 & 5.0 & $.09^{*}$ & $0 \%$ & $4.1 \%$ \\
\hline Lack of anger & -20 to 20 & -13 to 19 & 9.0 & 7.0 & $.09^{*}$ & $0 \%$ & $0 \%$ \\
\hline Lack of denial & -16 to 16 & -7 to 15 & 5.0 & 5.0 & $.10^{* *}$ & $0 \%$ & $0 \%$ \\
\hline $\begin{array}{l}\text { Reliance on } \\
\text { professional } \\
\text { help }\end{array}$ & -12 to 12 & -6 to 12 & 4.0 & 5.0 & $.09^{*}$ & $0 \%$ & $1.6 \%$ \\
\hline \multicolumn{8}{|l|}{ Outpatient group } \\
\hline MOT-Q total ${ }^{\mathrm{a}}$ & -62 to 62 & -49 to 51 & 17.0 & 19.2 & .07 & $0 \%$ & $0 \%$ \\
\hline $\begin{array}{l}\text { Interest in } \\
\quad \text { rehabilitation }\end{array}$ & -14 to 14 & -14 to 14 & 3.8 & 6.0 & $.11^{*}$ & $1.1 \%$ & $1.1 \%$ \\
\hline Lack of anger & -20 to 20 & -16 to 18 & 5.0 & 6.0 & .09 & $0 \%$ & $0 \%$ \\
\hline Lack of denial $^{\mathrm{a}}$ & -16 to 16 & -12 to 16 & 6.0 & 8.1 & $.09^{*}$ & $0 \%$ & $2.2 \%$ \\
\hline $\begin{array}{l}\text { Reliance on } \\
\text { professional } \\
\text { help }\end{array}$ & -12 to 12 & -8 to 12 & 3.0 & 4.0 & $.16^{* *}$ & $0 \%$ & $1.1 \%$ \\
\hline
\end{tabular}

${ }^{\mathrm{a}} N=91$; one patient had three missing values for the Lack of denial subscale, therefore no subscale or total score was calculated.

${ }^{* *}$ Significant at the .01 level; * Significant at the .05 level.

$\mathrm{IQR}=$ Inter Quartile Range; MOT-Q = Motivation for Traumatic Brain Injury Rehabilitation Questionnaire

differed between patients. In the outpatient group, $73.9 \%$ of patients answered all items, $23.9 \%$ had a maximum of three missing items, and $2.2 \%$ of outpatients had four or five missing items. For five items, at least three inpatients had a missing value: "I'm better now than I ever was" $(n=3)$; "Rehabilitation has nothing to do with my needs" $(n=4)$; "I have always had the problems I'm having now" $(n=4)$; "I don't have time for rehab" $(n=3)$; and "Going through rehabilitation will help me get (or keep) a job" $(n=3)$. In the inpatient group, less than $40 \%$ of patients chose the answer undecided for any item. In the outpatient group, more than $40 \%$ of patients were undecided on two items about the amount of therapy ("Given a choice I would spend more time in therapy", 41.3\%; and "I'd ask my therapists to do extra therapy tasks", 51.1\%) and two items about patients' trust in therapists ("Rehabilitation therapists can't help me with my problems", $41.3 \%$; and "Therapists would have me do things that are irrelevant", 53.3\%). 


\section{Floor and ceiling effects}

For the MOT-Q total as well as the subscale scores, less than $15 \%$ of patients obtained the lowest possible score indicating an absence of floor effects. Also, less than $15 \%$ of patients obtained the highest possible score demonstrating an absence of ceiling effects (Table 2). None of the patients obtained the lowest or highest possible MOT-Q total score. With regard to the subscales, five inpatients and one outpatient had the highest possible score for the Interest in rehabilitation subscale. For the Lack of denial subscale, two outpatients obtained the highest possible score. Regarding the Reliance on professional help subscale, two inpatients and one outpatient obtained the highest score. No patient in either group obtained the highest or lowest possible score for the Lack of anger subscale.

\section{Item-total correlations}

For 29 of 31 MOT-Q items, small to large significant item-total MOT-Q correlations were found in the inpatient group $(r=.18-.69)$ and the outpatient group ( $r=.28-.66)$. With the exception of two items in the inpatient group: "I'm better now than I ever was", $r=.18$; "Rehabilitation will help me get (or keep) a job", $r=.28$; and one item in the outpatient group: "Rehabilitation will help me get (or keep) a job" $r=.28$; all significant item-total MOT-Q correlations were moderate to large in magnitude.

In the inpatient group, two items in the Lack of denial subscale showed no significant association with the MOT-Q total score ("At first I had some problems, but I'm fine now", $r=-.03, p=.75$; and "I have some problems, but I'm doing fine", $r=-.05, p=.57)$. In the outpatient group, non-significant item-total MOT-Q correlations were found for one Lack of anger item ("My problems are my own business", $r=.12, p=.26$ ) and for one Reliance on professional help item ("I'd do what a therapist tells me even if it doesn't make sense", $r=.19, p=.07$ ).

\section{Internal consistency}

In both groups, good internal consistency was found for the MOT-Q total score $(\alpha=.85-.86)$ and for the Reliance on professional help subscale $(\alpha=.70-.73)$. Internal consistency of the subscales, Interest in rehabilitation, and Lack of denial, was acceptable in the inpatient group $(\alpha=.66, \alpha$ $=.63$, respectively) and good in the outpatient group $(\alpha=.83, \alpha=.84$, respectively). With regard to Lack of anger, internal consistency was good in the inpatient group $(\alpha=.80)$ and acceptable in the outpatient group $(\alpha=.68)$. 


\section{Inter-correlations between MOT-Q scores}

In Table 3, Spearman correlations between MOT-Q scores are presented. In both groups, the MOT-Q total score showed large, significant associations with all four subscales $(r=.56-.84)$. Three of the subscales, Lack of anger, Interest in rehabilitation, and Reliance on professional help, showed moderate to large, significant intercorrelations $(r=.31-.50)$. The Lack of denial subscale showed moderate to large, significant associations with Lack of anger $(r=.38-.49)$ and small to moderate, significant associations with Interest in rehabilitation $(r=.21-.29)$. With regard to Lack of denial and Reliance on professional help, no significant association was found in the inpatient group $(r=.04, p=.64)$ and a small, significant association in the outpatient group $(r=.24, p=.02)$.

\section{Criterion validity}

In Table 3, Spearman correlations between the MOT-Q and measures of selfawareness and treatment motivation can be found. In the outpatient group, a moderate, significant association was found between Lack of denial and self-

TABLE 3

Spearman correlations between MOT-Q scores and domain-specific measures

\begin{tabular}{|c|c|c|c|c|c|}
\hline & \multicolumn{5}{|c|}{ Spearman correlation coefficients: outpatient group - inpatient group } \\
\hline & $M O T-Q$ total & $\begin{array}{l}\text { Interest in } \\
\text { rehabilitation }\end{array}$ & $\begin{array}{c}\text { Lack of } \\
\text { anger }\end{array}$ & Lack of denial & $\begin{array}{c}\text { Reliance on } \\
\text { professional } \\
\text { help }\end{array}$ \\
\hline MOT-Q total & 1.00 & & & & \\
\hline $\begin{array}{l}\text { Interest in } \\
\text { rehabilitation }\end{array}$ & $.74^{* *}$ to $.72^{* *}$ & 1.00 & & & \\
\hline Lack of anger & $.84^{* *}$ to $.80^{* *}$ & $.48^{* *}$ to $.46^{* *}$ & 1.00 & & \\
\hline Lack of denial & $.56^{* *}$ to $.74^{* *}$ & $.21^{*}$ to $.29^{* *}$ & $.38^{* *}$ to $.49^{* *}$ & 1.00 & \\
\hline $\begin{array}{l}\text { Reliance on } \\
\text { professional } \\
\text { help }\end{array}$ & $.63^{* *}$ to $.58^{* *}$ & $.50^{* *}$ to $.38^{* *}$ & $.38^{* *}$ to $.31^{* *}$ & .04 to $.24^{*}$ & 1.00 \\
\hline $\begin{array}{l}\text { PCRS } \\
\text { self-awareness }^{\mathrm{a}}\end{array}$ & -.28 to -.10 & -.18 to -.17 & -.13 to -.17 & $-.44^{* *}$ to -.07 & .07 to -.04 \\
\hline $\begin{array}{c}\text { VAS Treatment } \\
\text { Motivation }^{\mathrm{b}}\end{array}$ & $.50^{* *}$ to N/A & $.37^{* *}$ to $\mathrm{N} / \mathrm{A}$ & $.42^{* *}$ to N/A & $.26^{*}$ to $\mathrm{N} / \mathrm{A}$ & $.36^{* *}$ to $\mathrm{N} / \mathrm{A}$ \\
\hline
\end{tabular}

${ }^{* *}$ Significant at the .01 level; ${ }^{*}$ Significant at the .05 level.

${ }^{a}$ The PCRS was completed by 66 outpatients and 107 inpatients.

${ }^{\mathrm{b}}$ The VAS Treatment Motivation was completed by 84 outpatients.

MOT-Q $=$ Motivation for Traumatic Brain Injury Rehabilitation Questionnaire; N/A = Not administered; PCRS $=$ Patient Competency Rating Scale; VAS = Visual Analogue Scale. 
awareness $(r=-.44, p<.001)$; more denial was related to poorer selfawareness. In the inpatient group, these measures were not significantly associated $(r=-.07, p=.46)$. The VAS Treatment Motivation was only administered to the outpatient group. It showed a significant, large association with the MOT-Q total score $(r=.50, p<.001)$, and small to moderate, significant associations with the MOT-Q subscales: Interest in rehabilitation $(r=.37, p=.001)$, Lack of anger $(r=.42, p<.001)$, Lack of denial $(r=.26, p=.018)$, and Reliance on professional help $(r=.36, p=.001)$.

\section{DISCUSSION}

The psychometric properties of the MOT-Q were evaluated in two groups of patients with $\mathrm{ABI}$. The results showed adequate feasibility, no floor or ceiling effects, significant item-total MOT-Q associations for the vast majority of items, and significant intercorrelations between most MOT-Q scores. The MOT-Q total and subscales demonstrated acceptable to good internal consistency. Furthermore, the MOT-Q total and subscales were significantly associated with a measure of treatment motivation. The Lack of denial subscale showed non-significant to moderately significant associations with a measure of self-awareness.

The feasibility of the MOT-Q for ABI rehabilitation was supported by the low number of missing responses in both groups. Further, in the outpatient group there were a high number of "undecided" responses for four items that referred to the amount of therapy and trust in therapists. Possibly, outpatients who were undecided had insufficient experience with therapy to be able to answer these items at the time of assessment. Another possibility is that outpatients chose "undecided" to avoid potential negative consequences of their answer (e.g., agreeing with "Therapists would have me do things that are irrelevant"). Of note are the additional analyses that revealed that outpatients' overall motivation (median $=17.0$ ) was significantly lower compared to the inpatient group (median $=25.4)$. Outpatients' scores were comparable to the scores reported in the original validation study (mean $=17.4$ ) (Chervinsky et al., 1998). A possible explanation for the low scores in the latter two groups is that, in contrast to the inpatient group, outpatients may have been less likely to receive a rehabilitation treatment at the time of completion of the MOT-Q or did not expect to receive rehabilitation in the near future. It is possible that patients who do not require or expect to receive a rehabilitation treatment soon, are less motivated for rehabilitation than patients who will actually receive treatment.

Besides having good feasibility, the vast majority of MOT-Q items showed significant associations with the MOT-Q total score. This indicates that nearly all items measured the same construct, i.e., motivation for rehabilitation. In 
both patient groups, there were only two items that were not associated with the MOT-Q total score and hence seemed to measure a different construct. In the inpatient group, this was the case for the Lack of denial items, "At first I had some problems, but I'm fine now" and "I have some problems, but I'm doing fine". These items may have measured a patient's abilities relative to other patients. In the outpatient group, the items, "My problems are my own business", and "I'd do what a therapist tells me even if it doesn't make sense", may have assessed a patient's locus of control. Before deleting items with a low item-total correlation from the MOT-Q, further research is needed to confirm the questionnaire's factor structure

On subscale level, the pattern of significant associations between the MOT-Q subscales was in agreement with previous findings (Lenze et al., 2004; Lequerica et al., 2006). All subscales showed significant intercorrelations with the exception of Lack of denial and Reliance on professional help in the inpatient group. The lack of a significant association in the inpatient group may be explained by psychometric limitations of the Lack of denial subscale in that group (i.e., two of eight items showed non-significant item-total correlations; inadequate criterion validity). Further, acceptable to good internal consistency was found for the four subscales and good internal consistency for the MOT-Q total score. This is also in accordance with previous studies (Bains et al., 2007; Chervinsky et al., 1998).

The finding that all MOT-Q scores were significantly associated with a measure of treatment motivation provides support for the criterion validity of the MOT-Q. In other words, the MOT-Q total and all subscales seem to measure aspects of motivation for rehabilitation. In contrast with our hypothesis, the MOT-Q subscale, Lack of denial, showed non-significant or only moderately significant associations with self-awareness. This may be explained by differences between the two measures. Denial and self-awareness are generally considered two conceptually different constructs. Denial denotes a coping strategy that serves to protect a patient from stressors, whereas self-awareness reflects the ability to appraise one's strengths and weaknesses (Toglia \& Kirk, 2000). The self-awareness measure (i.e., the PCRS) was based on the discrepancy between patient and psychologist ratings. The Lack of denial subscale only evaluates awareness from the individual's own perspective. Additional analyses revealed no significant differences in Lack of denial scores between inpatients and outpatients, but significantly lower self-awareness for inpatients compared to outpatients. On the one hand it is possible that inpatients showed poor self-awareness but no denial. On the other hand, inpatients' poor self-awareness may have influenced their Lack of denial scores. Patients with poor self-awareness are known to overestimate their functioning which may have influenced their Lack of denial scores. Hence, when interpreting the Lack of denial subscale score, one should take into account a patient's level of self-awareness. 
A limitation of the current study is that the MOT-Q factor structure could not be evaluated due to the small number of patients in both studies. Prevalent rules-of-thumb range from 5 to 10 patients per item which in the case of the MOT-Q would suggest 155 to 310 patients. Larger studies are needed to confirm the MOT-Q factor structure. A second limitation is that the VAS Treatment Motivation was only administered in the outpatient group. Since inconsistent results were found between the inpatient and outpatient group for the criterion validity of the Lack of denial subscale, it is possible that the MOT-Q scores would also show different associations with the VAS Treatment Motivation for the inpatient group versus the outpatient group. Third, the MOT-Q scores were only compared to the VAS-scale scores and were not compared to other patient-rated instruments of treatment motivation such as the more recently developed Stroke Rehabilitation Motivation Scale (SRMS; White et al., 2012). The SRMS was not available at the start of our study. Different motivation questionnaires measure different aspects of motivation, and may therefore yield other results on criterion validity. Fourth, the criterion validity of the subscales Lack of anger, Interest in Rehabilitation, and Reliance on professional help, were not examined since validated comparable measures were not available. Finally, the MOT-Q was administered by a clinician which may have induced socially desirable responding.

Although the MOT-Q is a valid instrument for research purposes, there are some practical issues that need to be considered when using the MOT-Q in clinical practice. First, it is important to note that higher scores on the MOT-Q do not per se imply better motivation. For instance, a patient with an internal locus of control may not agree with the item, "I rely on doctors to help me with my problems", but still may be highly motivated for treatment. Second, high scores may reflect socially desirable responding. For instance, some patients might be reluctant to admit to not wanting to follow treatment advice in order to avoid making a negative impression. Last, the MOT-Q should not be used merely to label patients as motivated or unmotivated as this may negatively influence patient care (Maclean, Pound, Wolfe, \& Rudd, 2000). It should rather be used to explore underlying causes of low participation during therapy. Herewith, the MOT-Q results should be interpreted in conjunction with clinical judgement to confirm poor motivation for rehabilitation.

In conclusion, the results of this study provide support for the validity of the MOT-Q total score to assess motivation for rehabilitation in patients with ABI. Further research is needed to examine the reliability and validity of the subscales. At this point, we recommend interpreting the MOT-Q total score in conjunction with the individual items. Caution is needed when interpreting scores at the subscale level. 


\section{REFERENCES}

Al-Adawi, S., Powell, J. H., \& Greenwood, R. J. (1998). Motivational deficits after brain injury: A neuropsychological approach using new assessment techniques. Neuropsychology, 12, $115-124$.

Bains, B., Powell, T., \& Lorenc, L. (2007). An exploratory study of mental representations for rehabilitation based upon the Theory of Planned Behaviour. Neuropsychological Rehabilitation, 17, 174-191.

Butcher, J. N., Dahlstrom, W. G., Graham, J. R., Tellegen, A., \& Kaemmer, B. (1989). Manual for the restandardized Minnesota Multiphasic Personality Inventory: MMPI-2. Minneapolis: University of Minnesota Press.

Chervinsky, A. B., Ommaya, A. K., de Jonge, M., Spector, J., Schwab, K., \& Salazar, A. M. (1998). Motivation for Traumatic Brain Injury Rehabilitation Questionnaire (MOT-Q): Reliability, factor analysis, and relationship to MMPI-2 variables. Archives of Clinical Neuropsychology, 13, 433-446.

Cohen, J. (1988). Statistical power analysis for the behavioral sciences (2nd ed.) Hillsdale, NJ: Lawrence Erlbaum Associates.

Deelman, B. G., Koning-Haanstra, M., Liebrand, W. G. B., \& Van de Burg, W. (1987). Handleiding van de SAN test. Lisse: Swets en Zeitlinger.

Lenze, E. J., Munin, M. C., Quear, T., Dew, M. A., Rogers, J. C., Begley, A. E., \& Reynolds, C. F. (2004). The Pittsburgh Rehabilitation Participation Scale: Reliability and validity of a clinician-rated measure of participation in acute rehabilitation. Archives of Physical Medicine and Rehabilitation, 85, 380-384.

Lequerica, A. H., Rapport, L. J., Whitman, R. D., \& Millis, S. R. (2006). Psychometric properties of the Rehabilitation Therapy Engagement Scale when used among individuals with acquired brain injury. Rehabilitation Psychology, 51, 331-337.

Maclean, N., Pound, P., Wolfe, C., \& Rudd, A. (2000). Qualitative analysis of stroke patients' motivation for rehabilitation. British Medical Journal, 321, 1051-1054.

Maclean, N., Pound, P., Wolfe, C., \& Rudd, A. (2002). The concept of patient motivation. A qualitative analysis of stroke professionals' attitudes. Stroke, 33, 444-448.

Marin, R. S., \& Wilkosz, P. A. (2005). Disorders of diminished motivation. Journal of Head Trauma Rehabilitation, 4, 377-388.

Medley, A. R., \& Powell, T. (2010). Motivational interviewing to promote self-awareness and engagement in rehabilitation following acquired brain injury: A conceptual review. Neuropsychological Rehabilitation, 20, 481-508.

Prigatano, G. P., Fordyce, D. J., Zeuner, H. K. et al. (1986). Neuropsychological rehabilitation after brain injury. Baltimore, MD: The Johns Hopkins University Press.

Smeets, S. M. J., Ponds, R. W. H. M., Verhey, F. R., \& Van Heugten, C. M. (2012). Psychometric properties and feasibility of instruments used to assess awareness of deficits after acquired brain injury: A systematic review. Journal of Head Trauma Rehabilitation, 27, $433-442$.

Smeets, S. M. J., Ponds, R. W. H. M., Wolters Gregório, G., Pouwels, C. G. J. G., Visscher, A. J., Winkens, I., \& Van Heugten, C. M. (2014). Impaired awareness of deficits in individuals with neuropsychiatric symptoms after acquired brain injury: Associations with treatment motivation and depressive symptoms. Neuropsychology, 28, 717-725.

Terwee, C. B., Bot, S. D. M., De Boer, M. R., Van der Windt, D. A. W. M., Knol, D. L., Dekker, J., .. De Vet, H. C. W. (2007). Quality criteria were proposed for measurement properties of health status questionnaires. Journal of Clinical Epidemiology, 60, 34-42.

Toglia, J., \& Kirk, U. (2000). Understanding awareness deficits following brain injury. NeuroRehabilitation, 15, 57-70. 
Van den Broek, M. D. (2005). Why does neurorehabilitation fail? Journal of Head Trauma Rehabilitation, 20, 464-473.

Wade, D. T., \& Collin, C. (1988). The Barthel ADL Index: A standard measure of physical disability? International Disability Studies, 10, 64-67.

White, G. N., Cordato, D. J., O' Rourke, F. O., Mendis, R. L., Ghia, D., \& Chan, D. K. Y. (2012). Validation of the Stroke Rehabilitation Motivation Scale: A pilot study. Asian Journal of Gerontology and Geriatrics, 7, 80-87.

Winkens, I., Van Heugten, C. M., Visser-Meily, J. M. A., \& Boosman, H. (2014). Impaired selfawareness after acquired brain injury: Clinicians' ratings on its assessment and importance for rehabilitation. Journal of Head Trauma Rehabilitation, 29, 153-156. 